Shihab : Simulation Of Chlorine Concentrations In Mosul University's Distribution...

\title{
Simulation Of Chlorine Concentrations In Mosul University's Distribution Network Using EPANET Program
}

\section{Mohammed S. Shihab, Abdullah I. Al-Hyaly, Mayada H. Mohammad}

Civil Engineering Department, College of Engineering, University of Mosul, Mosul, Iraq

\begin{abstract}
The objective of this study was to demonstrate a real-time chlorine decay with enhancement of simulation program (EPANET 2.0) developed for drinking water supply networks. Periodically samples, two runs/week at various time intervals, were tested at (20) locations in water distribution system of Mosul University and analyzed in site with chlorinator instrument. First the system hydraulic model (EPANET) was used with the entire pipe and junction data which was obtained from university's records, while chlorine decay coefficients (both bulk and wall) were used from previous literatures and some model runs. A value of the bulk decay coefficient of $\left(-1.0 \mathrm{~d}^{-1}\right)$ was chosen, as for the wall decay coefficient, it was set to zero.

The study demonstrated that most of the highly water consumption nodes have a residual chlorine concentration within $(0.25-1.2) \mathrm{mg} / \mathrm{l}$. Moreover, the simulation program shows that from (12 - 5 A.M) chlorine concentration has nil values .However, due to the lack of maintenance works in both storage tank and piping network, about $93 \%$ of the reaction rates of the chlorine were happened in, so it is recommended to add an adequate dosing of chlorine with appropriate mixing in the high elevated tank.
\end{abstract}

KEYWORDS: simulation, chlorine decay, water quality, distribution networks, EPANET

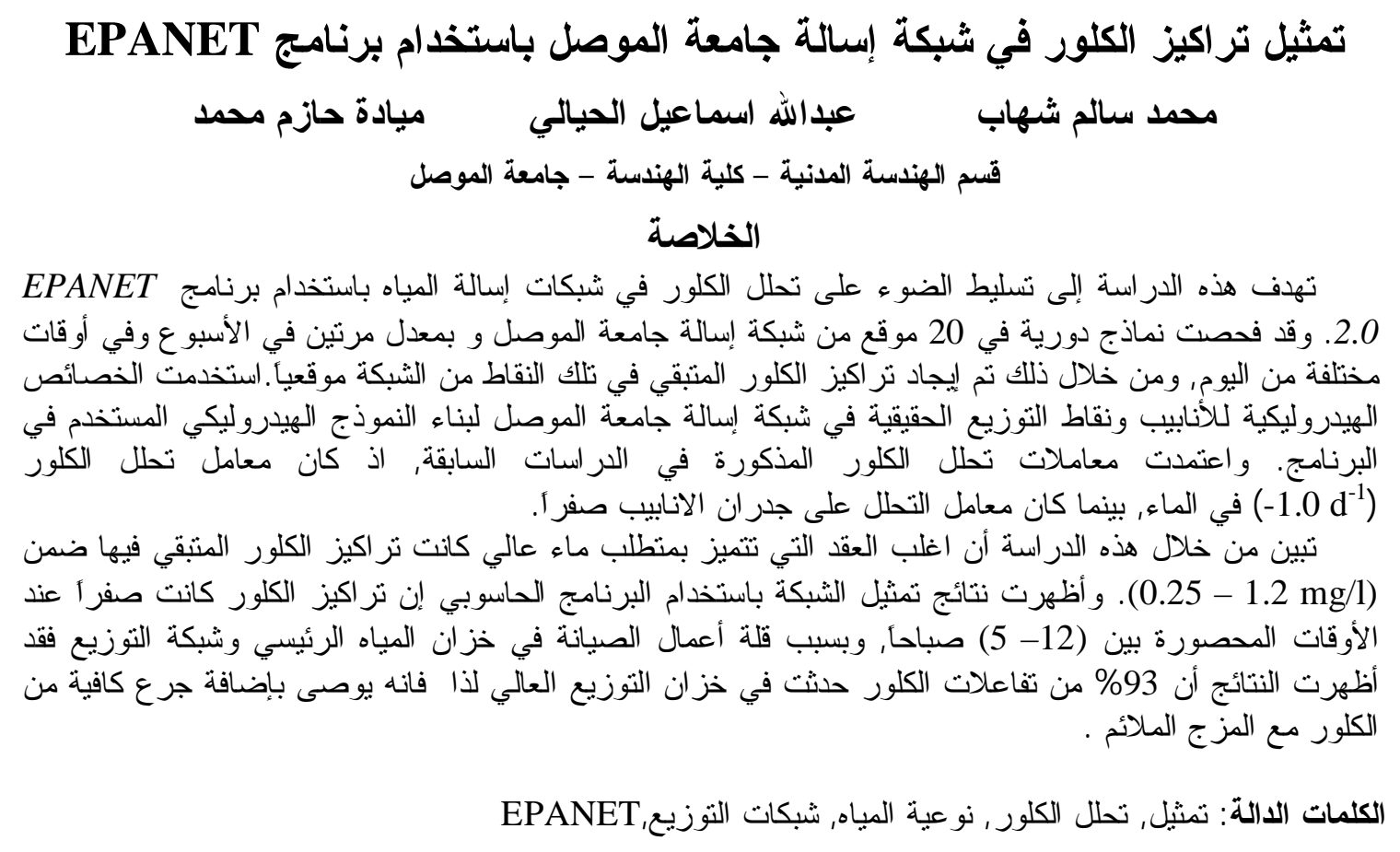

Received 9 Oct 2008

Accepted 9 Feb. 2009 


\section{Al-Rafidain Engineering $\quad$ Vol.17 $\quad$ No.6 $\quad$ Dec. 2009 \\ Introduction}

Water quality is a prime concern in the world. Many transmittable diseases are waterborne and, therefore, the treatment and maintenance of the quality of water is Paramount to public health. Water distribution networks serve many purposes in addition to the provision of water for human consumption, which often accounts for less than $2 \%$ of the total volume supplied. Networks are designed to meet peak demands; in parts of the network this creates low-flow conditions that can contribute to the deterioration of microbial and chemical water quality. To maintain microbial quality, the network should be designed and operated to prevent ingress of contaminants, to maintain disinfectant residual concentrations within a locally predetermined range and to minimize the transit time [1].

Typically, chlorine is added near the final stages of drinking water treatment plants to disinfect. A certain residual amount is added to disinfect against any pathogens found in the inside walls of the distribution system piping [2]. This residual chlorine is consumed on its journey through the piping system and the chlorine concentration should be at low concentrations at the point of consumption. This is difficult to manage, due to the complexities of the distribution system and the randomness at which consumers use water [3]; [ 4];[ 5]. However, excessive amounts of chlorine are harmful to human health, while chlorine concentrations too low to effectively kill bacteria and viruses will not properly disinfect the water [6]. In addition, disinfection by-products have been proven carcinogenic [7].

Computer-based mathematical models that able to predict the time history and the spatial distribution of constituents in water distribution networks are useful in network design and operation. Such models can be used to analyze water quality degradation problems, to assess alternative operational and control strategies for improving and maintaining water quality, and to evaluate water quality aspects of distribution network improvement projects. Several researchers have proposed models of this type that consider advection and reaction and neglect dispersion and several computer programs, that implement such models are available [6].Field observations conducted in distribution networks have shown that the advection reaction model predictions are in good agreement with the observed concentrations in pipes with medium and high flow velocities, but fail in dead-end pipes where low velocities prevail [8]; [9].

The water quality models that are incorporated in virtually all modern network simulators were developed in order to simulate the movement, mixing and transformation of chemical or biochemical water quality parameters that may be considered to be completely diluted in the water carried by the system [10]; [11]; [12]; [13]. In addition, such models are capable of determining travel time between any two points (often referred to as residence time or water age), as well as tracing the proportion of water passing through any node that originates in any other given node.

\section{Description Of Computer Model}

EPANET is a public-domain, water-distribution-system modeling package developed by the U.S. Environmental Protection Agency's Water Supply and Water Resources Division .The computer software model used to model relies upon the hydraulic analysis engine to compute friction head losses based on the Hazen-Williams equation. EPANET models a water distribution system as a collection of links connected to nodes. The links represent pipes, pumps, and control valves [14].

It performs extended-period simulation of hydraulic and water-quality behavior within pressurized pipe networks and is designed to be a research tool that improves our understanding of the movement and fate of drinking-water constituents within distribution 


\section{Shihab : Simulation Of Chlorine Concentrations In Mosul University's Distribution...}

systems. the basic assumptions present in this type of models usually include complete instantaneous mixing at junction nodes and the absence of longitudinal mixing effects in pipes [15]; [16]. However, certain formulations also propose longitudinal dispersion (both molecular diffusion and eddy dispersion) as a quantifiable effect, especially for low velocity hydraulic regimes [17]; [11].

\section{Formulation}

The advection or transport process is fundamentally modeled by the equations of hydraulic equilibrium [12]; [18]. Specifically by the values of flow or velocity in each pipe and at each moment in time (Figure 1).

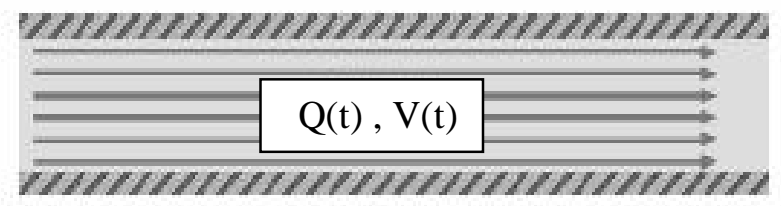

\section{Figure(1): Advection or transport with flow[19]}

EPANET"s water quality simulator uses a lagrangian time - based approach to track the fate of discrete parcels of water as they move along pipe and mix together at junctions between fixed - length time steps. Modeling the mixing process that takes place at any junction node with more than one contributing pipe, including external supply, assumes instantaneous complete mixing and is ruled by the law of mass conservation (Figure2).

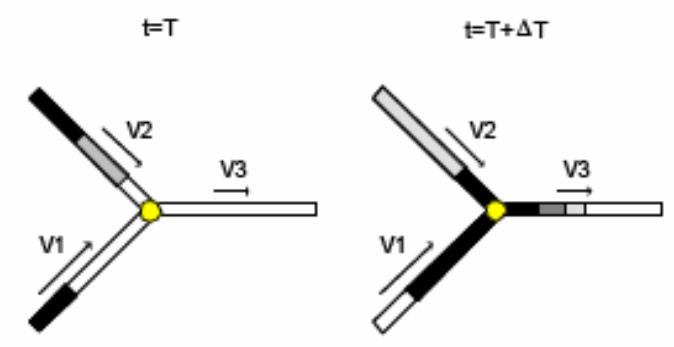

Figure (2): Complete mixing at junction nodes [19]

At each moment in time, given any two or more pipes that contribute to a particular node and that carry different concentrations of the same parameter, the concentration of that parameter in all pipes leaving the node is homogeneous and corresponds to the complete mix of the contributing concentrations in the proportion of the respective flows. The non-steady advection-dispersion-reaction process in a pipe flowing full is described by the following partial differential equation [20].

$\frac{\partial C}{\partial t}+u \frac{\partial C}{\partial x}=D \frac{\partial^{2} C}{\partial x^{2}}-K C$

Where

$C=$ constituent concentration (mass/vol).

$u=$ cross-sectional average flow velocity (length / time).

$D=$ dispersion coefficient (length / time).

$K=$ first order decay constant (1/ time).

$X=$ distance along pipe (length unit)

$t=$ time 


\section{$\begin{array}{llll}\text { Al-Rafidain Engineering } & \text { Vol.17 } & \text { No.6 } & \text { Dec. } 2009\end{array}$}

The following boundary conditions hold at the network nodes:

- At some nodes, as constituent sources, the concentration $C$ is given as a prescribed function of time.

- Mixing at the network nodes. Two or more pipes, each of them with different flow and constituent concentration, may convey inflow to a node. Water is mixed at the node and a new concentration is obtained, then water leaves the node with that concentration to the out flowing pipes and to the consumption abstracted. A complete and instantaneous mixing is usually assumed in the network models.

- Mass conservation at the network nodes. The well-known differential equation (1), is obtained by applying the mass conservation principle to an elementary pipe segment with a length $(d x)$ in a time period $(d t)$, such that $(d x=u . d t)$. The same derivation can be generalized to the case of a junction where several pipes meet. Given that the flow velocity $(u j$ )in each pipe $(j)$ is different, the segment length of each pipe considered in the elementary node volume will be different in order to handle the balance of the incoming and out coming quantities in the same period of time $(d t)$, so that $(d x j=u j . d t)$.

The following nodal equivalent of equation (1) is thus obtained:

$\sum_{j=1}^{m}\left(\frac{d x_{j}}{2} A_{j}\right) \frac{\partial C}{\partial t}=\sum_{j=1}^{m}\left(A_{j} D_{j} \frac{\partial C}{\partial x}+Q_{j} C-K_{j} A_{j} C \frac{d x_{j}}{2}\right)-q_{j} C$

Where

$m=$ number of pipes connected to the node.

$A j=$ cross sectional area of pipe $j$.

$Q j=$ flow rate in pipe $j$ ( vol / time).

$D j=$ dispersion coefficient of chlorine in pipe $j$ (length / time).

$K j=$ first order decay constant of chlorine in pipe $j$ (1/ time).

$q j=$ flow rate abstracted at the node ( vol / time).

For the case where two pipes of equal characteristics meet at the node and $q j=0$, the equation (2) reduces to the equation (1) if $d x j$ and $d t$ tend to be infinitesimally small

- Mass balance at the storage tanks connected to the network.

Under completely mixed conditions the concentration throughout the tank is a blend of the current contents and that of any entering water. At the same time, the internal concentration could be changing due to reactions.

The chlorine decay and propagation models available to date treat the pipe segments as if they were a chemical reactor [21]. For such a chemical reactor it is assumed that chlorine enters from one end, decays in water (bulk decay) due to reaction with organisms and is consumed around the pipe wall due to a biofilm attached to the pipe wall and transported to the other end of the pipe by convection. Chlorine may also react with the pipe itself if the pipe consists of iron. The chlorine decay (reaction) and transport mechanism is schematically described in Figure (3). 


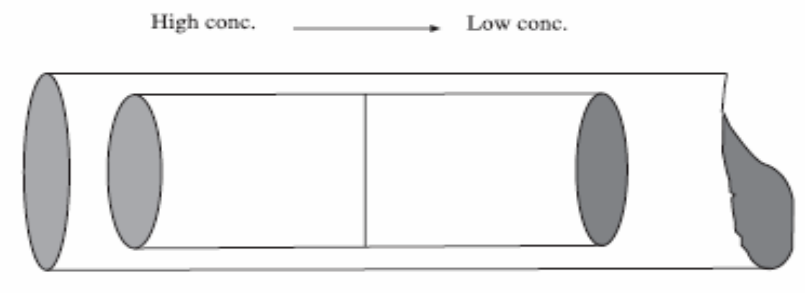

Axial Convection and Bulk Decay

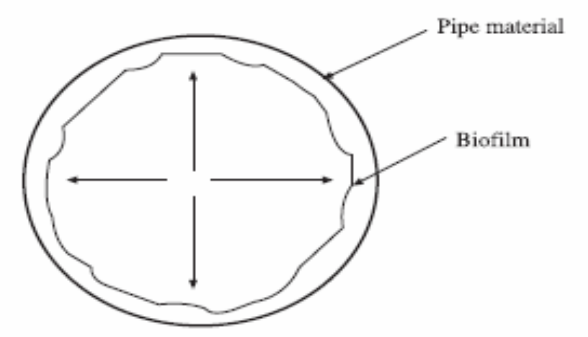

Radial Diffusion and Pipe Wall Demand

Figure 3: Schematic Description of 2-D Chlorine Transport[21]

In most of the studies to date [22]; [9]; [23]. The chlorine decay mechanism has been treated as two dimensional (2-D). The first dimension is the longitudinal axis of the pipe along which chlorine is transported and decayed (bulk decay). The second dimension is the radial direction along which chlorine is transported because of velocity gradients and diffuses due to the high pipe wall consumption.

The development of the chlorine decay and transport equations is summarized as follows:

The one-dimensional (1-D) equation of chlorine decay at any time or distance in a pipe is given as [23].

$C_{1 D}=\frac{c_{t}}{c_{\tau-1}}=\exp \left\{-\left(k+W_{d} / r_{0}\right)\right\} t$

Where

$C_{1 D}=$ non-dimensional 1-D chlorine decay.

$C t=$ chlorine concentration at any time $\mathrm{t}$ (mass / vol).

$\mathrm{C}_{\mathrm{t}-1}=$ chlorine concentration at time $\mathrm{t}-1$ (or initial chlorine concentration in the pipe) (mass / vol).

$\mathrm{Wd}=$ pipe wall chlorine demand (length $/$ time).

$\mathrm{K}=$ chlorine decay in water (bulk decay) (1 / time).

$r_{0}=$ pipe radius (length unit).

$t=$ travel time of water (convection).

\section{Requirements for Simulation}

The requirements for water quality analyses depend on the type of application. Broadly speaking, the application of water quality models falls into three general Categories [24]:

- Planning/Design--These studies define system configurations, size or locate facilities, or define long-term operating policies. They adopt a long-term perspective but, under Current practices, utilize short, hypothetical scenarios based on representative initial Conditions and operating conditions. In principle, the statistical distribution of system conditions should be an important consideration, but in practice variability is considered only by analyses intended to represent worst-case conditions. 


\section{Al-Rafidain Engineering $\quad$ Vol.17 $\quad$ No.6 $\quad$ Dec. 2009}

- Operations--These short-term studies analyze a scenario that is expected to occur in the immediate future so as to inform immediate operational decisions. These are based on current system conditions and expected operating conditions.

- Forensics--These studies are used to link presence of contaminants to the risk or actual occurrence of disease. Depending on whether the objective is cast in terms of acute or chronic exposures, the study may adopt a short- or long-term perspective.

However, data needed for the simulation include:

- Network information: topology; length, diameter, and roughness coefficient of each pipe.

- Demands and boundary conditions: demands at nodes; elevations; given head at sources and tanks.

- Total duration of the simulation.

- Water quality characteristics (chemical, physical, and biological).

- Network system characteristics (loops, dead-ends).

- Mixing of waters (different source waters).

\section{Methodology}

Periodically samples, tow runs/week at various time intervals, were taken at (20) random locations of use in the distribution system of Mosul University, where chlorine concentration and pressure values were analyzed in site with chlorinator and barometric gauge instruments respectively for calibration purposes ,as illustrative in table (1).

It is crucial to know the details of the network layout and hydraulics before taking any step into quality modeling. First the system hydraulic model (EPANET) was set up with all of the pipe and junction data. Pipe and junction data was obtained from university's maintenance directorate, while chlorine decay coefficients (both bulk and wall) were obtained from literature and some model runs. Bulk chlorine decay coefficient values found in the literature consist of a range of (- 0.01 to -1.0$) \mathrm{d}^{-1}$. A value of the bulk decay coefficient of $\left(-1.0 \mathrm{~d}^{-1}\right)$ was chosen as a max. value for demonstration purposes. As for the wall decay coefficient, it was set to zero because of about $85 \%$ of the network pipes made of P.V.C material which characterizes with a smooth surface of the internal pipe's wall. While source quality (chlorine) was set to $1.2 \mathrm{mg} / \mathrm{l}$ as field measurements .No demand pattern data was available except a system-wide average daily consumption. The junction-averaged system-wide value was used due to the lack of individual nodal demand values, depending on university's records for students and employs population, a virtual hourly demand fluctuation pattern was employed where peak demand was set through (10 A.M - 12 A.M) as shown in figure (4) .while the produced water were set according to pumping station operator's schedule that have not excessive capacity unless an increase in future demand is probable.

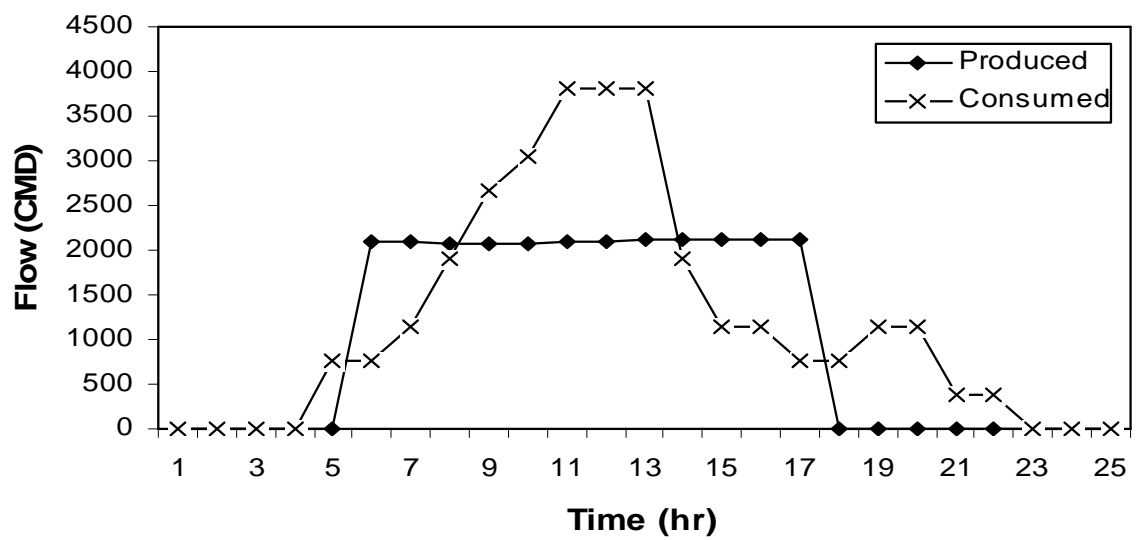

Figure (4): virtual hourly demand fluctuation pattern in Mosul University 
Shihab : Simulation Of Chlorine Concentrations In Mosul University's Distribution...

Table (1): Calibration data field for simulation.

\begin{tabular}{|c|c|c|c|c|}
\hline $\begin{array}{l}\text { Item } \\
\text { No. }\end{array}$ & Location & $\begin{array}{l}\text { Pressure } \\
\quad \text { (Psi) }\end{array}$ & $\begin{array}{l}\text { Chlorine } \\
\text { conc. }(\mathrm{mg} / \mathrm{l})\end{array}$ & Time (Hr: Min.) \\
\hline \multirow{4}{*}{1} & \multirow{4}{*}{$\begin{array}{l}\text { Administration of sciences } \\
\text { college. }\end{array}$} & 12 & 0.8 & 9:05 \\
\hline & & 29 & 0.0 & $12: 15$ \\
\hline & & 11 & 0.0 & $11: 55$ \\
\hline & & 10 & 0.1 & $12: 55$ \\
\hline \multirow{4}{*}{2} & \multirow{4}{*}{ Engineering Consultant bureau } & 36 & 1.2 & $9: 28$ \\
\hline & & 41 & 0.4 & $3: 10$ \\
\hline & & 38 & 0.0 & $12: 00$ \\
\hline & & 40 & 0.1 & $1: 00$ \\
\hline \multirow{4}{*}{3} & \multirow{4}{*}{ Central library } & 11 & 0.0 & $9: 25$ \\
\hline & & 33 & 1.2 & $3: 20$ \\
\hline & & 8 & 0.8 & $12: 05$ \\
\hline & & 10 & 0.6 & $1: 03$ \\
\hline \multirow{4}{*}{4} & \multirow{4}{*}{ bank } & 30 & 0.1 & $9: 10$ \\
\hline & & 39 & 0.4 & $3: 30$ \\
\hline & & 42 & 0.0 & $2: 02$ \\
\hline & & 42 & 0.3 & 1:07 \\
\hline \multirow{4}{*}{5} & \multirow{4}{*}{ Electrical engineering. dept. } & 34 & 1.2 & $9: 35$ \\
\hline & & 40 & 0.6 & $2: 55$ \\
\hline & & 37 & 0.6 & $12: 15$ \\
\hline & & 40 & 0.8 & $1: 15$ \\
\hline \multirow{4}{*}{6} & \multirow{4}{*}{ Eastern University's gate } & 36 & 1.2 & $9: 40$ \\
\hline & & 24 & 0.5 & $3: 00$ \\
\hline & & 37 & 0.2 & $12: 17$ \\
\hline & & 41 & 0.6 & $1: 18$ \\
\hline \multirow{4}{*}{7} & \multirow{4}{*}{ Computer engineering. Dept. } & 34 & 1.2 & $9: 45$ \\
\hline & & 38 & 0.4 & $2: 40$ \\
\hline & & 33 & 0.4 & $12: 27$ \\
\hline & & 38 & 0.8 & $1: 21$ \\
\hline \multirow{4}{*}{8} & \multirow{4}{*}{$\begin{array}{l}\text { College of computer \& math. } \\
\text { sciences }\end{array}$} & 60 & 1.2 & $9: 53$ \\
\hline & & 60 & 0.6 & $3: 35$ \\
\hline & & 60 & 0.5 & $12: 33$ \\
\hline & & 60 & 0.8 & $1: 35$ \\
\hline \multirow{4}{*}{9} & \multirow{4}{*}{ Pumping station } & 60 & 1.2 & $9: 55$ \\
\hline & & 60 & 0.8 & $2: 15$ \\
\hline & & 60 & 1.0 & $12: 37$ \\
\hline & & 60 & 0.8 & $1: 40$ \\
\hline \multirow{4}{*}{10} & \multirow{4}{*}{ Computer science dept. } & 60 & 1.2 & $10: 03$ \\
\hline & & 53 & 0.8 & $2: 10$ \\
\hline & & 60 & 1.0 & $12: 40$ \\
\hline & & 60 & 0.8 & $1: 44$ \\
\hline 11 & Programming sciences dept. & 45 & 0.5 & $10: 10$ \\
\hline
\end{tabular}




\begin{tabular}{|c|c|c|c|c|}
\hline \multicolumn{2}{|c|}{ Al-Rafidain Engineering } & \multicolumn{2}{|l|}{ Vol.17 } & \multirow{2}{*}{$\begin{array}{c}\text { Dec. } \mathbf{2 0 0 9} \\
2: 05\end{array}$} \\
\hline & & 51 & 0.8 & \\
\hline & & 50 & 0.3 & $1: 04$ \\
\hline & & 60 & 0.8 & $1: 44$ \\
\hline \multirow{4}{*}{12} & \multirow{4}{*}{ University stadium } & 41 & 0.8 & $10: 15$ \\
\hline & & 44 & 0.7 & $2: 25$ \\
\hline & & 46 & 1.0 & $1: 14$ \\
\hline & & 46 & 0.7 & $1: 52$ \\
\hline \multirow{4}{*}{13} & \multirow{4}{*}{ Agriculture college } & 34 & 0.7 & $10: 35$ \\
\hline & & 39 & 0.6 & $2: 35$ \\
\hline & & 42 & 0.5 & $1: 20$ \\
\hline & & 40 & 0.6 & $1: 59$ \\
\hline \multirow{4}{*}{14} & \multirow{4}{*}{ Sport college admin. } & 11 & 1.0 & $10: 45$ \\
\hline & & 18 & 0.5 & $1: 45$ \\
\hline & & 20 & 0.6 & $1: 26$ \\
\hline & & 16 & 0.2 & $2: 03$ \\
\hline \multirow{4}{*}{15} & \multirow{4}{*}{ Pharmacy college (new site) } & 16 & 0.8 & $10: 48$ \\
\hline & & 20 & 1.0 & $1: 35$ \\
\hline & & 60 & 0.6 & $1: 32$ \\
\hline & & 60 & 0.7 & $2: 09$ \\
\hline \multirow{4}{*}{16} & \multirow{4}{*}{ Dentist college admin. } & 17 & 0.1 & $10: 55$ \\
\hline & & 24 & 0.4 & $1: 25$ \\
\hline & & 30 & 0.5 & $1: 37$ \\
\hline & & 22 & 0.2 & $2: 13$ \\
\hline \multirow{4}{*}{17} & \multirow{4}{*}{ dental clinics } & 39 & 1.0 & $11: 00$ \\
\hline & & 19 & 1.2 & $1: 20$ \\
\hline & & 25 & 0.8 & $1: 41$ \\
\hline & & 16 & 0.3 & $2: 16$ \\
\hline \multirow{4}{*}{18} & \multirow{4}{*}{ University guards admin. } & 40 & 1.0 & $11: 10$ \\
\hline & & 41 & 0.8 & $12: 45$ \\
\hline & & 45 & 0.6 & $12: 45$ \\
\hline & & 42 & 0.7 & $2: 27$ \\
\hline \multirow{4}{*}{19} & \multirow{4}{*}{ Ethics college admin. } & 32 & 1.2 & $11: 15$ \\
\hline & & 31 & 0.4 & $12: 55$ \\
\hline & & 33 & 0.3 & $1: 04$ \\
\hline & & 32 & 0.4 & $2: 32$ \\
\hline \multirow{4}{*}{20} & \multirow{4}{*}{ earth quick center } & 25 & 0.4 & $11: 22$ \\
\hline & & 29 & 0.8 & $1: 08$ \\
\hline & & 30 & 0.4 & $1: 54$ \\
\hline & & 25 & 0.4 & $2: 40$ \\
\hline
\end{tabular}

\section{Results and Discussion}

For the all selected points on the study map (select in MrSID format); as shown in figure (5); A scenario includes two basic themes required to construct the model, namely, a node and a link theme. They contain all the necessary features and references to represent the network. 


\section{Shihab : Simulation Of Chlorine Concentrations In Mosul University's Distribution...}

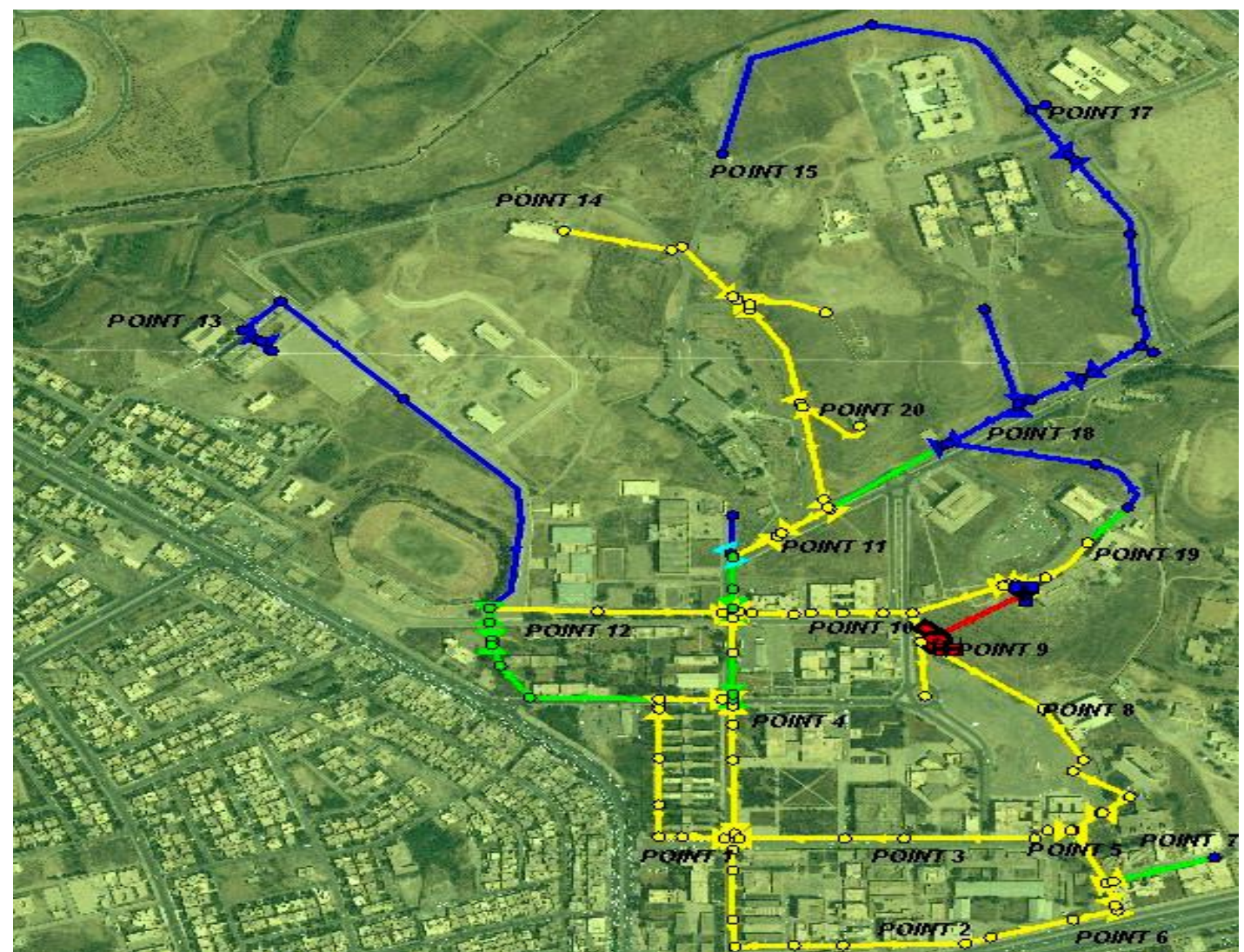

Figure (5): Scheme of the Water distribution system of Mosul University

The output of the simulated results showed that ,figure $(6,7)$,concentration of residual chlorine in the nodes (junctions) and pipes (links) at the $24^{\text {th }}$ hrs, is equal to zero and trace concentration respectively , as it was expected because of prevailing of the low flow velocity in the pipes, and the relatively high residence time in the network's nodes, privately at dead ends within the period ( 12 P.M - 5 A.M), where demand pattern was set to zero .

While at the pumping station, at the main feeding distribution network pipe, it's noticed that the simulated chlorine concentration was about $0.6 \mathrm{mg} / \mathrm{l}$.

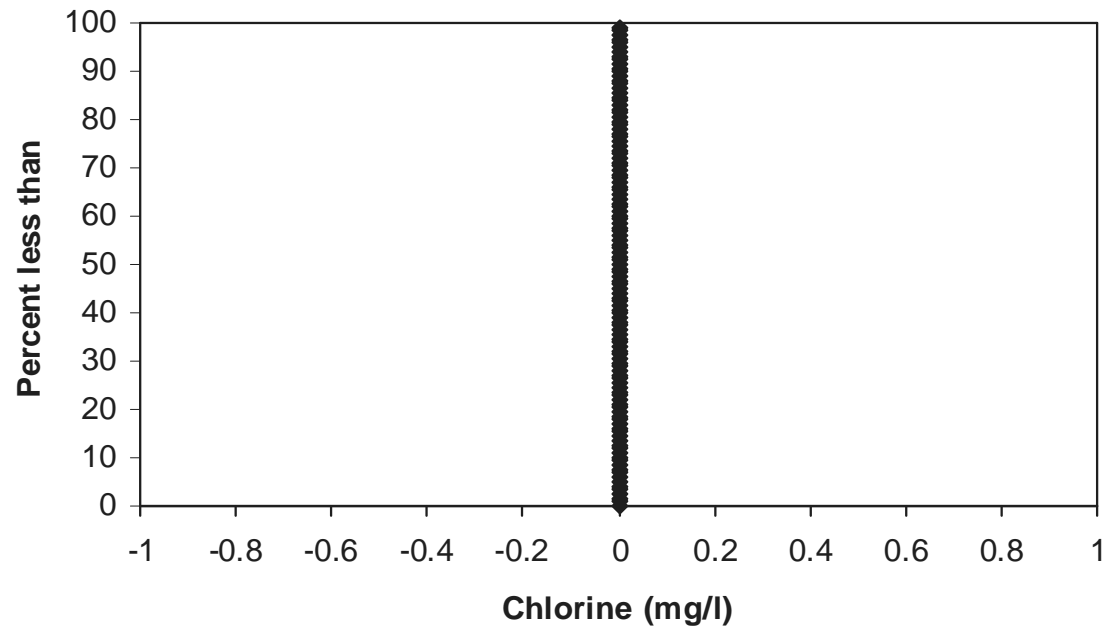

Figure (6): frequency distribution curves of residual chlorine concentration in the nodes at $24^{\text {th }} \mathrm{hr}$ 
Al-Rafidain Engineering $\quad$ Vol.17 $\quad$ No.6 $\quad$ Dec. 2009

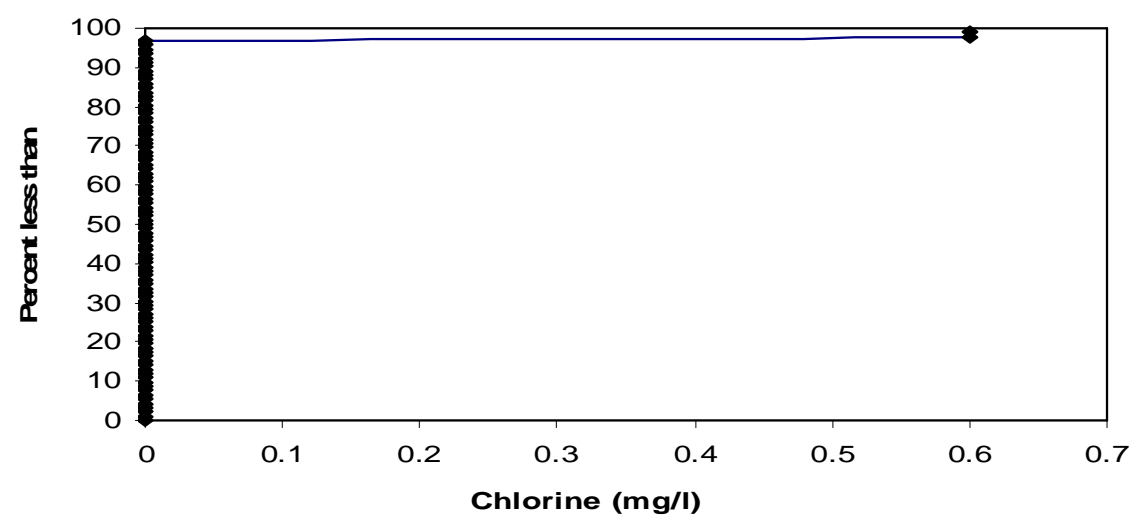

Figure (7): frequency distribution curves of residual chlorine concentration in the pipes at $24^{\text {th }} \mathrm{hr}$

Consequently, figures $(8,9)$ shows the frequency distribution curves of residual chlorine concentration in the nodes and pipes respectively at the $10^{\text {th }} \mathrm{hrs}$, where max. demand patterns were assumed, (90\%) of the output program readings were about $0.85 \mathrm{mg} / \mathrm{l}$ of chlorine concentration for both nodes and pipes. The turbulent pattern flow in pipes network, where the velocity ranged $(0.14-1.4) \mathrm{m} / \mathrm{sec}$, have an effect on chlorine concentration throughout agitation of the sediment that settled within the mid- night period (no demand) which would imposed a high bulk flow reactions with an advection-reaction domination.

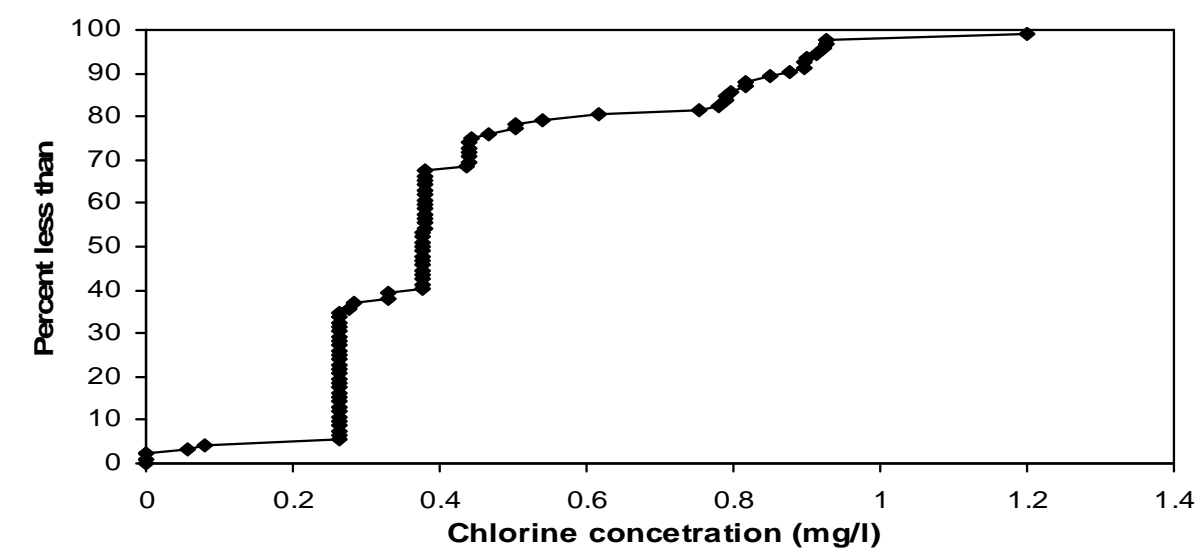

Figure(8): The frequency distribution curves of residual chlorine concentration in the nodes at $10^{\text {th }} \mathrm{hr}$

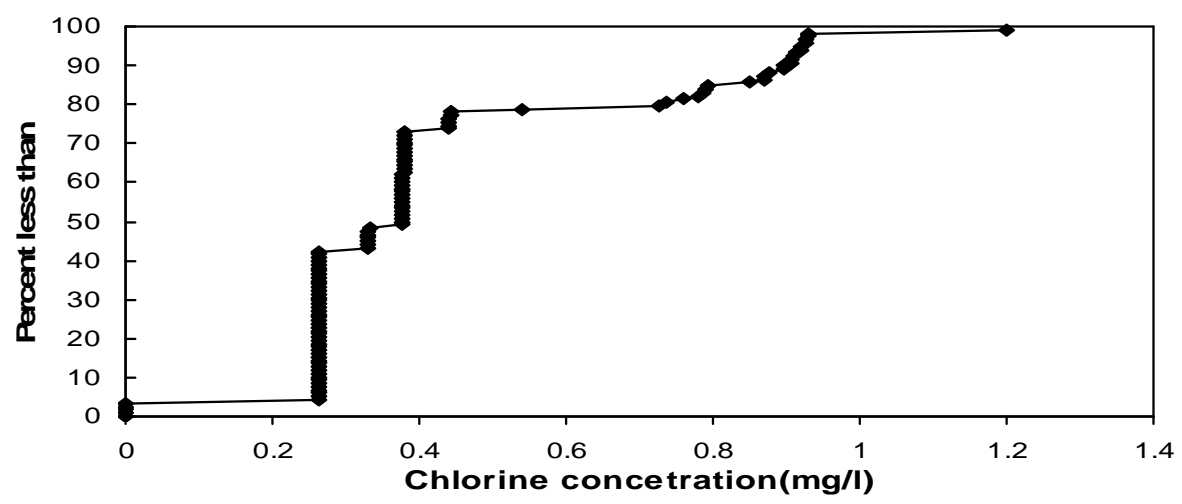

Figure(9): The frequency distribution curves of residual chlorine concentration in the pipes at $10^{\text {th }} \mathrm{hr}$ 


\section{Shihab : Simulation Of Chlorine Concentrations In Mosul University's Distribution...}

Despite of the above discussion that state that most of chlorine decay reaction rates would happened in pipes distribution network ,however, figure (10) shows that (93\% )of these reactions occurred in the high elevated tank (feeding source ).Essentially, this result may refers to the high age of water ,the factor that has the greatest overall effect on water quality, in the tank which extend (12-18 hrs), furthermore, the cumulative sediment in the tank basement and the lack of maintenance work.

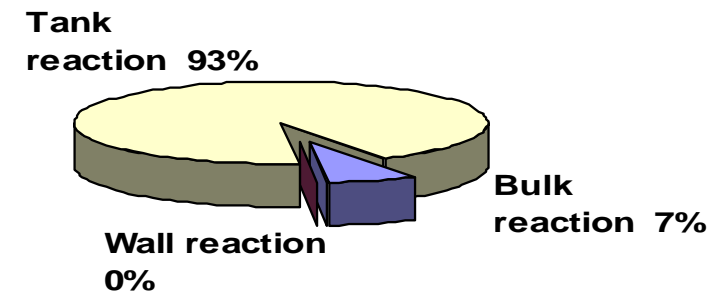

Figure (10): Percentages distribution of the average reaction rates in distribution system

Figs $(11, a-d)$ demonstrates that most of the simulated nodes have the same pattern of chlorine concentration variations with the exception of nodes (7), (9) and (15), computer engineering dept., pumping station and pharmacy college (new site) respectively.

The explication of node (9) simulated result, is that the relatively high concentration of chlorine in the feeding source at the pumping station. While, at node (7) and (15) the dead end nodes, the observed field data showed that chlorine concentration were ranged $(0.4-1.2) \mathrm{mg} / \mathrm{l}$ and $(0.6-1.0) \mathrm{mg} / \mathrm{l}$ respectively, conversely, the simulated data testify zero chlorine concentration allover $24 \mathrm{hrs}$ in both nodes ,this poor prediction may contribute to the advection reaction model that program depended on which has good agreement with the observed concentrations in pipes with medium and high flow velocities, but fail in dead-end pipes where low velocities prevail.

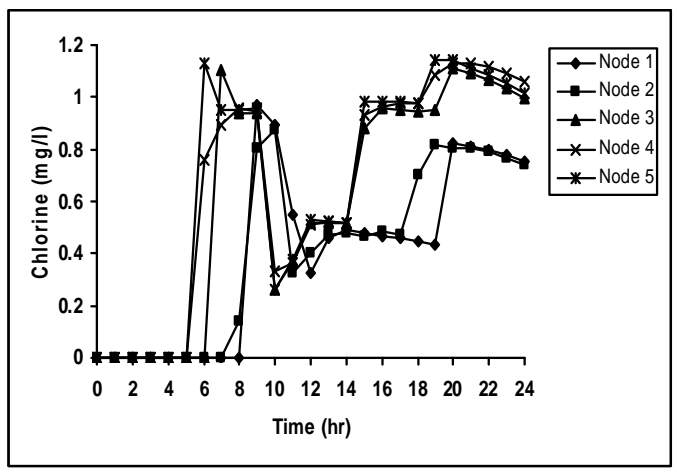

(a)

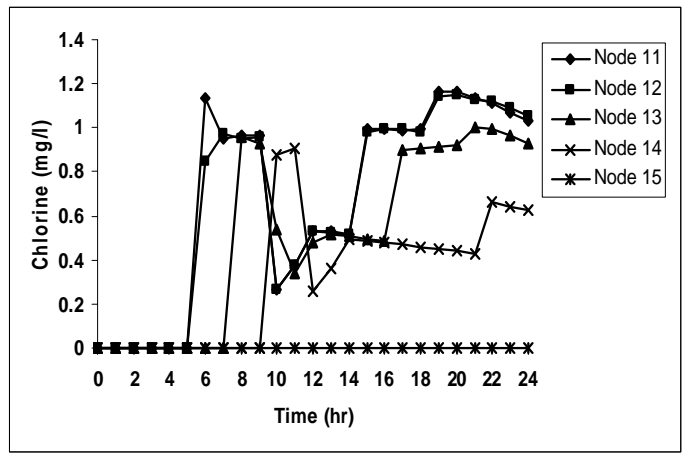

(c)

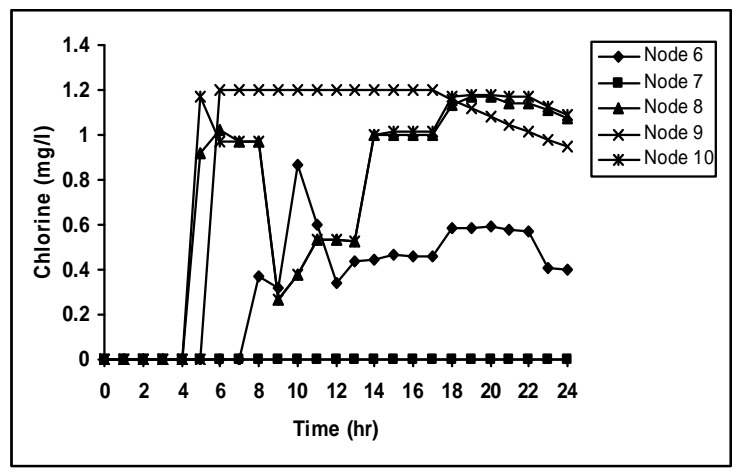

(b)

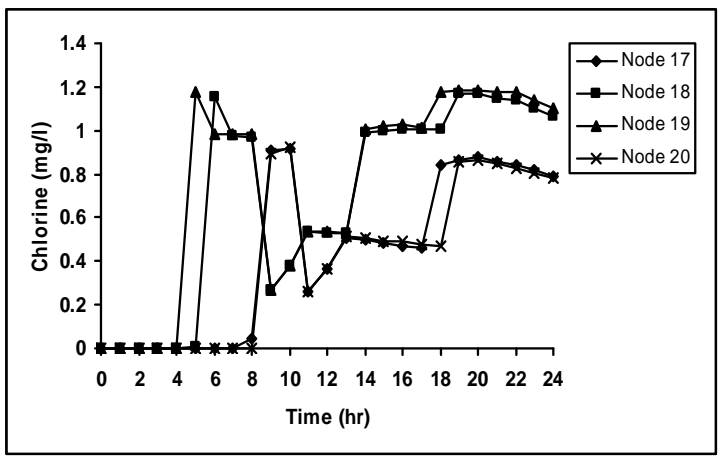

(d)

Figure (11): The 24 hrs variations in chlorine concentration at the selected nodes 


\section{Al-Rafidain Engineering $\quad$ Vol.17 $\quad$ No.6 $\quad$ Dec. 2009}

As one of the program's features in the statistical analysis, figs. $(12,13)$, Comprised a comparison of simulated (computed) and measured (observed) data of main values of chlorine concentration and pressure, where the Root Main Square (RMS) error was 0.337 with correlation factor between means 53.6\%. Obviously, there are variances in these results and that may contribute to:

- The assumption of highly consumption rates pattern that may differs from actual action.

- Assuming identical field conditions for network pipes (no cavities in internal surface wall pipe and no corrosions).

- There is no systematic operation schedule of the pump station which has a principle role in flow regime within network pipes.

- The assumption of bulk flow coefficient $\left(-1.0 \mathrm{~d}^{-1)}\right.$ as max. Value may not appropriate for all pipes material.

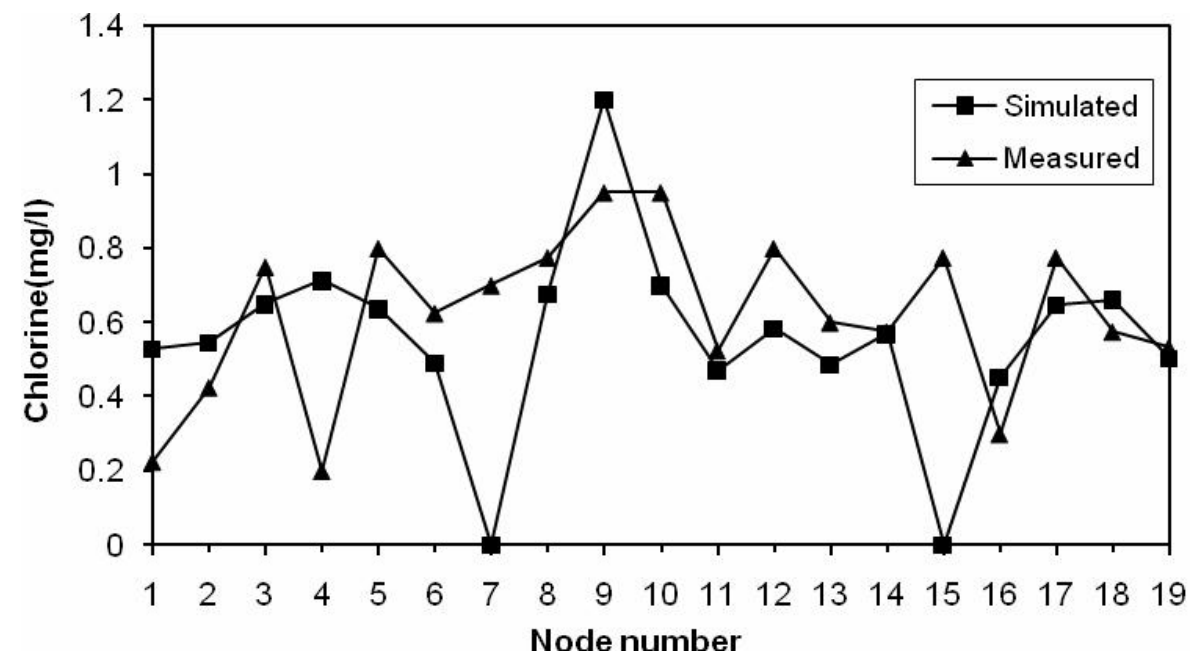

Figure (12): comparison of simulated and measured data of main values of chlorine concentration

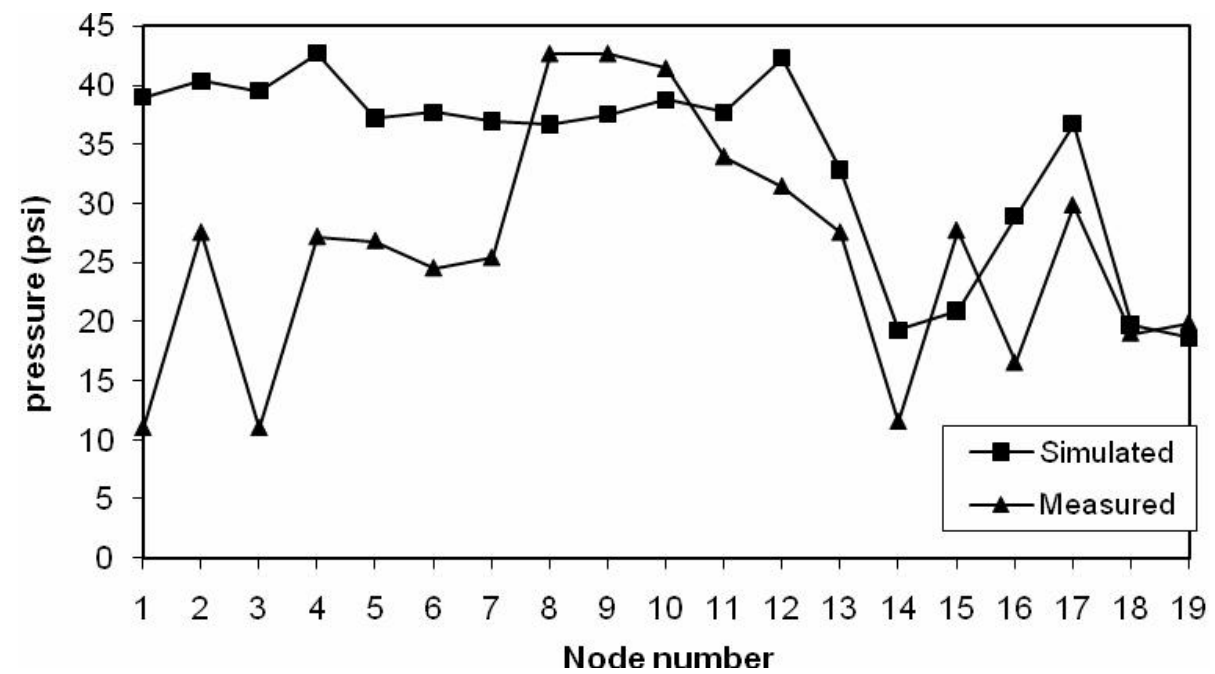

Figure (13): comparison of simulated and measured data of main values of pressure 


\section{Conclusion}

The study comes out with that most of highly water consumption nodes at peak consumption period (10 A.M - 12 P.M) have a residual chlorine concentration $(0.25-1.2 \mathrm{mg} / \mathrm{l})$. Farther more, the result showed that About $93 \%$ of the reaction rates of the chlorine were happened in the high elevated tank, that impose addition of adequate dosage of chlorine with appropriate mixing in the tank. Although that there are a variance in the simulated and observed data in chlorine concentration and pressure, it can be say that (EPANET) program have a relevant reliability in simulation of water quality in water distribution systems.

\section{References}

1. Kay Chambers, John Creasey and Leith Forbes. Design and operation of distribution Networks, 2004 World Health Organization. Safe Piped Water: Managing Microbial Water Quality in Piped Distribution Systems. Published by IWA Publishing, London, UK.

2. Mays, L. W. (Ed.). (2000). Water distribution systems handbook. New York, NY: McGraw-Hill, Inc.

3. Barkdoll, B.D (1992) Modeling instantaneous demands in municipal distribution system dead ends, MS thesis, University of Cincinnati, Cincinnati, Ohio.

4. Barkdoll, B.D. and Buchberger, S.G. (1992) "Modeling instantaneous residential demands in municipal water distribution systems," ASCE Proceedings of the Water Resources Sessions at Water Forum.

5. Meier, R.W. and Barkdoll, B.D. (2000) "Sampling design for network model calibration using genetic algorithms," Journal of Water Resources Planning and Management, v. 126, n. 4, Jul. 2000.

6. American Water Works Association Research Foundation and Environmental Protection Agency. Conference on Water Quality Modeling in Distribution Systems, Cincinnati, Ohio.

7. Viessman, W. and Hammer, M.J. (1998) Water Supply and Pollution Control, 6th ed., Addison Wesley, Menlo Park, CA.

8. Rossman L. The EPANET water quality model. In B. Coulbeck, editor, Integrated Computer Applications in Water Supply, pages 79-93, Taunton, England, 1993. Research Studies Press Ltd.

9. Rossman L., Clark .R, and Grayman W. Modeling chlorine residuals in drinkingwater distribution systems. Journal of Environmental Engineering, ASCE, 120(4):803-820., 1994.

10. Coelho, S., Loureiro, D., Alegre, H. (2006). Modeling and analysis of water supply systems. IRAR/ LNEC Technical Guides, Portugal.

11. Lansey, K., Boulos, P. (2005). Comprehensive handbook on water quality analysis. MWH Soft, USA.

12. Walski, T. M., Chase, D. V., Savic, D. A. (2003). Advanced Water Distribution Modeling. Haestad Methods Press, USA (www.haestad.com)

13. Rossman, L. A., Boulos, P. F. (1996). Numerical methods for modeling water quality in distribution systems: A comparison. J. Water Resour. Plan. Management, ASCE, 122(2), 137-146.

14. Rossman, L. A. (2000). EPANET 2 users manual, United States Environmental Protection Agency, Cincinnati, USA. 
15. Grayman, W.M., Clark, R.M., Males, R.M. (1988). Modeling distribution-system water quality: dynamic approach, J. Water Resources Planning and Management, ASCE, 114, (3), 295-311.

16. Liou, C.P., Kroon, J.R. (1987). Modeling the propagation of waterborne substances in distribution networks, J. American Water Works Association, November 1987, 54-58.

17. Zhang, W., Miller, C., DiGiano, F. (2004). Bacterial Regrowth Model for Water Distribution Systems Incorporating Alternating Split-Operator Solution Technique. J. Env. Eng. ASCE, September 2004 (932-941).

18. Cesario, L. (1995). Modeling, Analysis, and Design of Water Distribution Systems. American Water Works Association, Denver, USA.

19. Burkhard Wricke, Lars Henning, Andreas Korth;"Particles in relation to water quality deterioration and problems in the network", Techneau, 2007

20. Tzatchkov V.G., Aldama A.A., Arreguin F.I. A domain decomposition strategy for the numerical simulation of contaminant transport in pipe networks, Fourteenth International Conference on Domain Decomposition Methods , 2003 DDM.org

21. Ozdemir O. N., Sevuk S. Ger A. M.," DYNAQ: A Chlorine Decay Simulator in Water Supply Networks" Turk J Engin Environ Sci 24 (2000), 401 - 412.

22. Biswas P., Lu C. S., and Clark, R.M., IChlorine Concentration Decay in Pipes", Water Research Journal, 27(1224, 1993

23. Ozdemir O. N., Ger A. M., "Realistic Numerical Simulation of Chlorine Decay in Pipes", Water Research Journal, Vol. 32, No, 11 pp. 3307-3312, 1998

24. Marco Maglionico, Rita Ugarelli reliability of a water supply system in quantity and quality terms ,bologna university, distart, viale risorgimento, 2, 40136 bologna Italy. 